\title{
Elimination of High Quality Video Random Noise through Modified First Order Neighborhood Mean Filter (MFONMF)
}

\author{
V.Sujith ${ }^{1}$, B.Karthik ${ }^{2}$ \\ \{pcnsujith@gmail.com¹ ${ }^{1}$ karthik.ece@ bharathuniv.ac.in, karthikguru33@ gmail.com ${ }^{2}$ \}
}

Research Scholar, ECE, Bharath Institute of Higher Education and Research, Chennai ${ }^{1}$, Associate Professor, Department of ECE, Bharath Institute of Higher Education and Research, Chennai. $^{2}$

\begin{abstract}
Noise elimination is one amongst the foremost necessary elements to urge distinctive video from hugely corrupted video. The video could also be corrupted with noise for the period of broadcast from crying channel, sensors or thanks to various ecological circumstances. This constructs the video illustration ugly. Random noise also can rise up throughout transmission that staggeringly corrupts the video. During this paper a formula is meant to eliminate the random from corrupted color films. In earlier period investigator projected several algorithms to urge obviate the random noise however they be unsuccessful to produce higher effects at high noise density example $80 \%-90 \%$. The projected formula machinery on levels initial level is to return across the crying picture element and also the second stage is to update the crying picture element. This set of rules considers modified initial order neighborhood picture elements for sleuthing the crying pixel and imply filter is employed for de-noising. Color movies area unit de-noised with the helpful resource of extracting the each and every frame from video, then the frames area unit rending into $\mathrm{R}, \mathrm{G}$ and $\mathrm{B}$ channels once that they are denoised one by one once that united conjointly once more to make the color video.
\end{abstract}

Keywords: Video, Denising, Random Noise, MFONMF.

\section{Introduction}

Image sweetening is individual among the ranges for process the picture in digital picture process location. Image sweetening is that the device of constructing pictures additional helpful and it additionally get better the marvelous of photograph. the explanation why image sweetening is completed for the reason that it highlights attention-grabbing information inside the picture graph gets obviate noise from the representation and construct the photo visually attractive. There area unit immense directions of photograph sweetening ways spatial space approach and frequency place approach. Spatial fieldpractice works unswervingly on the exploitation of photograph pixels when frequency neighborhood is predicated entirely on written material the Fourier or wave renovate of image. If treatment is meted out quickly on picture pixels and if the picture is vociferous this shows any superfluous statistics is introduced to the picture then de-noising is dead in additives exposure of noise and elimination of that specific noise. Noise ordinarily comes from sensors, ecological things and transmission via vociferous channel. De-noising is accomplished thanks to the truth the 
photograph is perhaps visually ugly, awful compression or terrible assessment. There are unit exclusive noise sorts freelance of spatial place and spatially structured. The noises that area unit freelance of spatial neighborhood area unit impulsive noise and AWGN and therefore the spatially dependent noise considers periodic noise.

\section{Literature Review}

For casting off the noise beginning the dishonored photograph filter is done where distinct sorts of sieve are used for noise elimination. These filters hold back the noise from the representation and make the photo noise loose. Several filters planned by means of way of remarkable researchers for disposing of the noise from the pictures which might be corrupted by using way of desire noise and they will be the most excellent choice to dispose of noise as they're easy to position into effect on hardware. Dissimilar filters that have been used embody middle filter, suggest clean out, toggle median filter, alpha trimmed mean clear out, unsymmetric trimmed median clear out and so on. Numerous researchers have advised numerous filtering strategies for eradicate salt and pepper noise. Among those SMF is easy to execute and is likewise dependable.

Drawback: Nevertheless, its critical downside filter is effectual high-quality at squat down density. When concentration stage is accelerated over $50 \%$ then the brink statistics of specific photograph isn't preserved [4]. To triumph over this disadvantage several techniques have been projected to do away with salt and pepper noise at excessive density. A Fast Adaptive Mean Filtering Algorithm

\section{Proposed Algorithm}

The proposed clamor evacuation the utilization of MFONMF set of rules systems each and every pixel of the body by utilizing recognizing the uproarious pixel in the casing of video. This arrangement of principles is construct absolutely with respect to windowing strategy so a minimum length window $4 \times 3$ is taken from each collection of video to diminish the unpredictability. Pixel of intrigue is the inside pixel called preparing pixel $P(1, \mathrm{j})$. Preparing pixel is checkered whether it's miles uproarious or commotion free with the helpful asset of confirming that the pixel lies between most (255) and insignificant (0) dark degree esteems. On the off chance that the pixel is in the middle of the assortment of dim level then the pixel is without commotion generally the pixel is adulterated pixel and it is handled to get supplanted to clamor free pixel expense. Innocent pixels that lounge inside the variety are left unaltered.

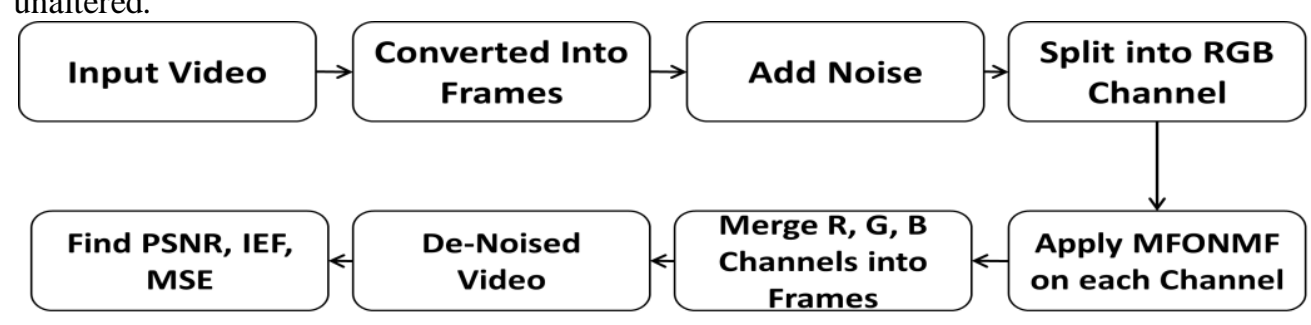

Figure 1- Block Diagram of MFONMF 


\section{Flow Chart}

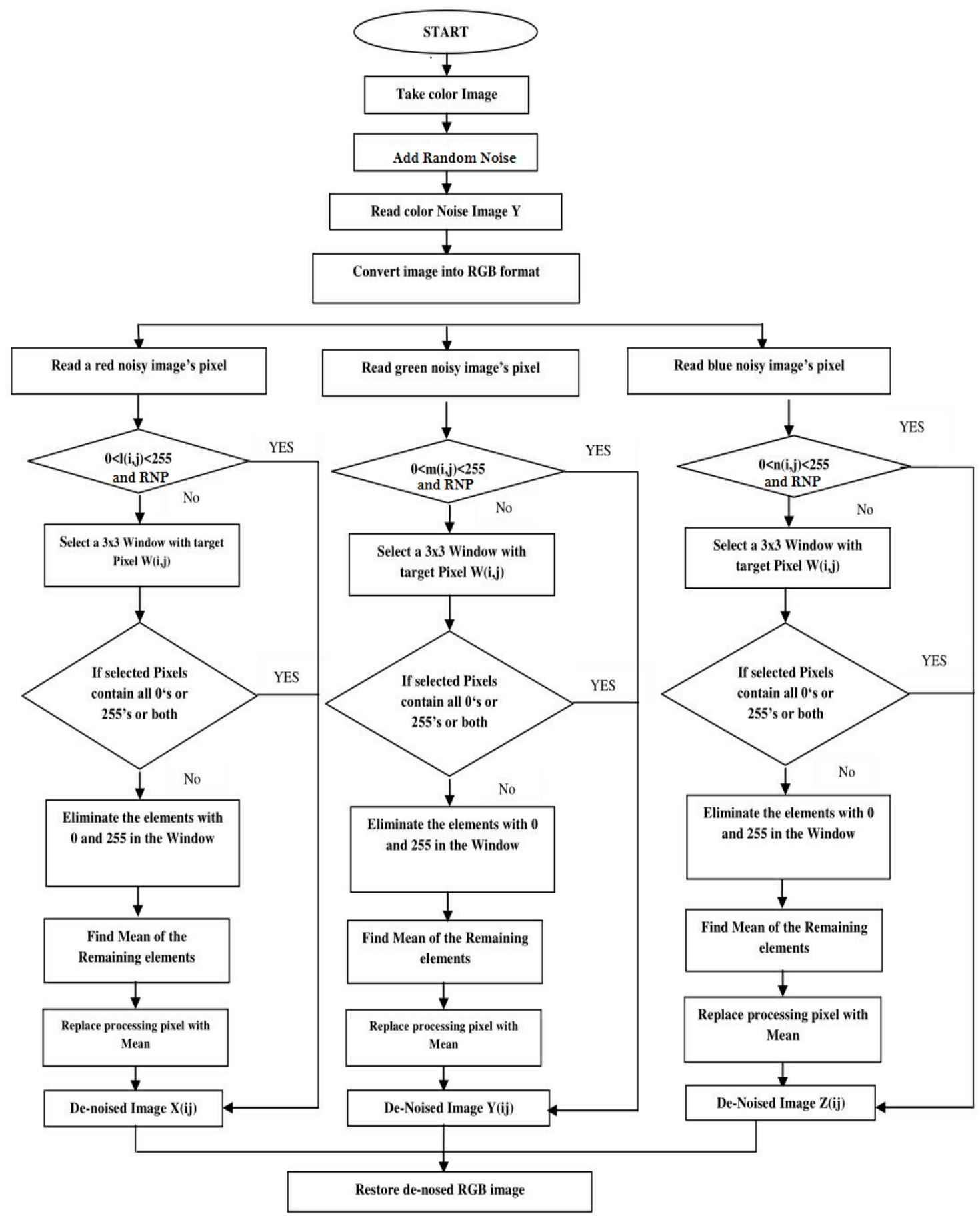

Figure 2. Flowchart of Proposed Algorithm MFONMF 


\section{Procedure for MFONMF}

The steps for the algorithm are as follows:-

The steps for the algorithm are as follows:-

S1: First we take an preliminary shade frame from video and be appropriate on it constant appreciated impulse noise. This colour frame is read as Y [1] and similarly all processing frames are stored within the form of array $\mathrm{Y}$.

$\mathrm{Y}$ [1: No of frames].

S2: In the 2nd step break up the frame hooked on RGB thing. Captivating BGR pixels for inspection noise.

S3: In 3rd step the pixel is examine and progression with the aid of the usage of the subsequent steps:-

$\mathrm{S} 3.2$ : 2nd step we determination exertion on noisy pixel of $\mathrm{S} 3.1$ now pick a window $\mathrm{W}$ (i, $\mathrm{j}$ ) of size $2 \mathrm{X} 2$. Take for granted that the dispensation noisy pixels are $X(i, j)$, this is process within the subsequent step.

Step 3.3: Then circulate the desired window across one step of all four directions (left, proper, top, and backside) as proven in underneath parent. Now discover the mean price for all windows then replace $\mathrm{X}$ with the calculated over all suggest price from all windows. This noise removed frame restores in denoised frame on the final step.

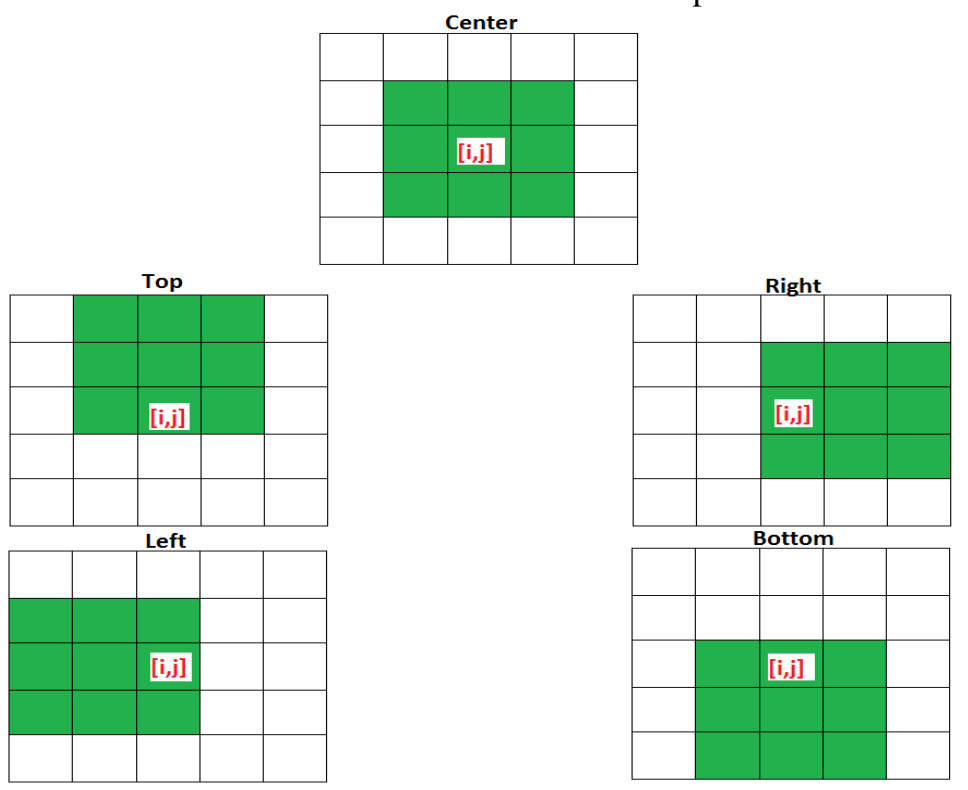

Figure 3. Sample window selection for de-noising

Step four: Replicate S3.I to 3.3 for BGR additives. Noisy pixel are correspond to by using $\mathrm{m}(\mathrm{i}, \mathrm{j})$ and for B noisy pixel are correspond to by $\mathrm{n}(1, \mathrm{j})$. Also the re-establish body is represent by $\mathrm{Y}(1, \mathrm{j})$ and $\mathrm{Z}(1, \mathrm{j})$ correspondingly.

Step 5: Complete development is achieved until all pixels pink, $G$ and $B$ within the entire frame are development. And subsequently the BGR mechanism are compound to get the ultimate denoised frame. 
Step 6: Extracted frames are merged into the denoised coloration video.

Hence a better denoised video is obtain with improved PSNR, IEF and additionally indicates a higher video with extremely stumpy blur and stepped forward visible and human perception

\section{Formula}

Performance are quantitatively calculated with numerous noise density for PSNR, MSEand IEF defined (1), (2) and (3) correspondingly:

$$
\begin{aligned}
& P S N R=10 \log _{10} \frac{(255)^{2}}{M S E} \\
& M S E=\frac{\sum_{i=1}^{m} \sum_{j=1}^{n}\{Y(i, j)-\hat{Y}(i, j)\}^{2}(2)}{m \times n} \\
& I E F=\frac{\sum_{i=1}^{m} \sum_{j=1}^{n}\{\eta(i, j)-Y(i, j)\}^{2}}{\sum_{i=1} \sum_{j=1}(\hat{Y}(i, j)-Y(i, j))^{2}}(3)
\end{aligned}
$$

Here $\mathrm{kx} 1$ is the dimensions of the pictureture. Y (i, j) symbolize the unique image and $\mathrm{Y}^{\gamma}(\mathrm{i}, \mathrm{j})$ symbolize denoised photo and $\eta(\mathrm{i}, \mathrm{j})$ symbolize noisy picture. The noise concentration is speckled from $10 \%$ to $90 \%$. The consequences display advanced presentation.

\section{Results}

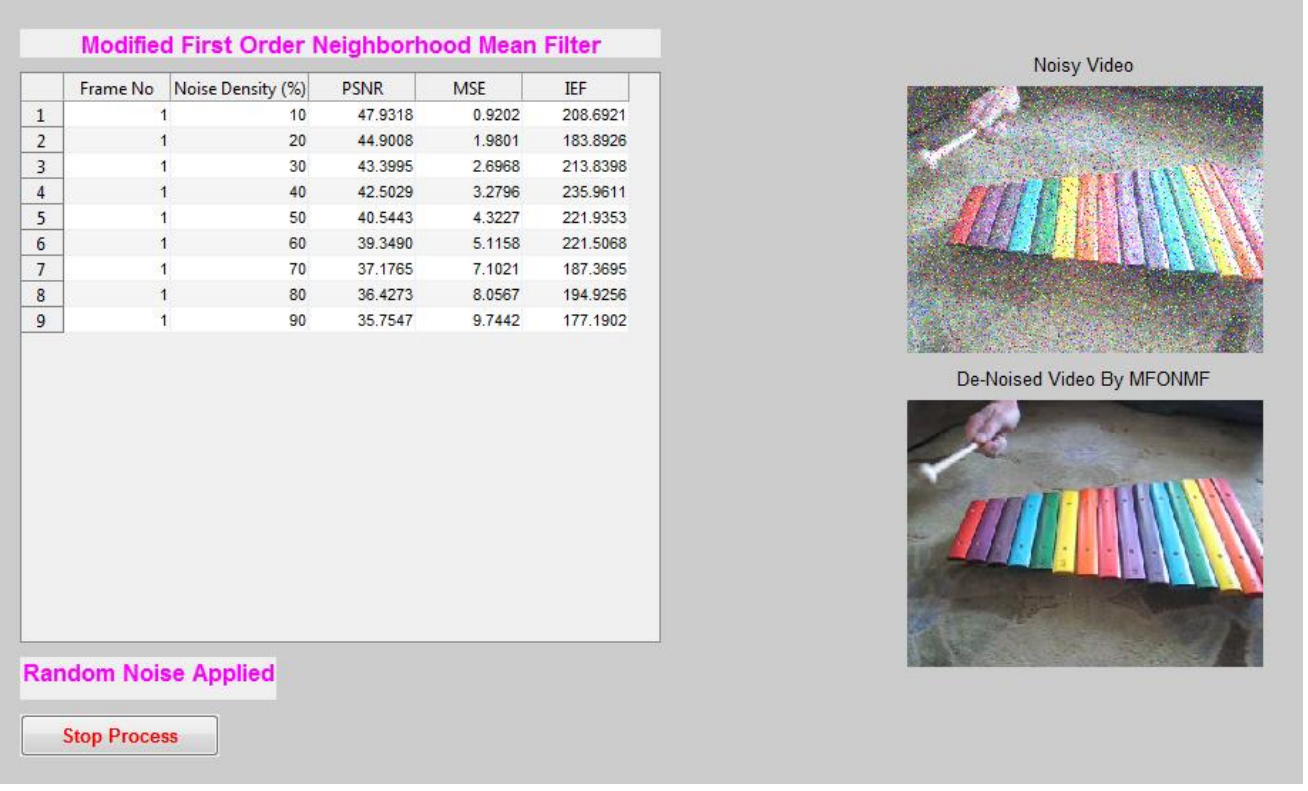

Figure 7 Proposed filter Output 


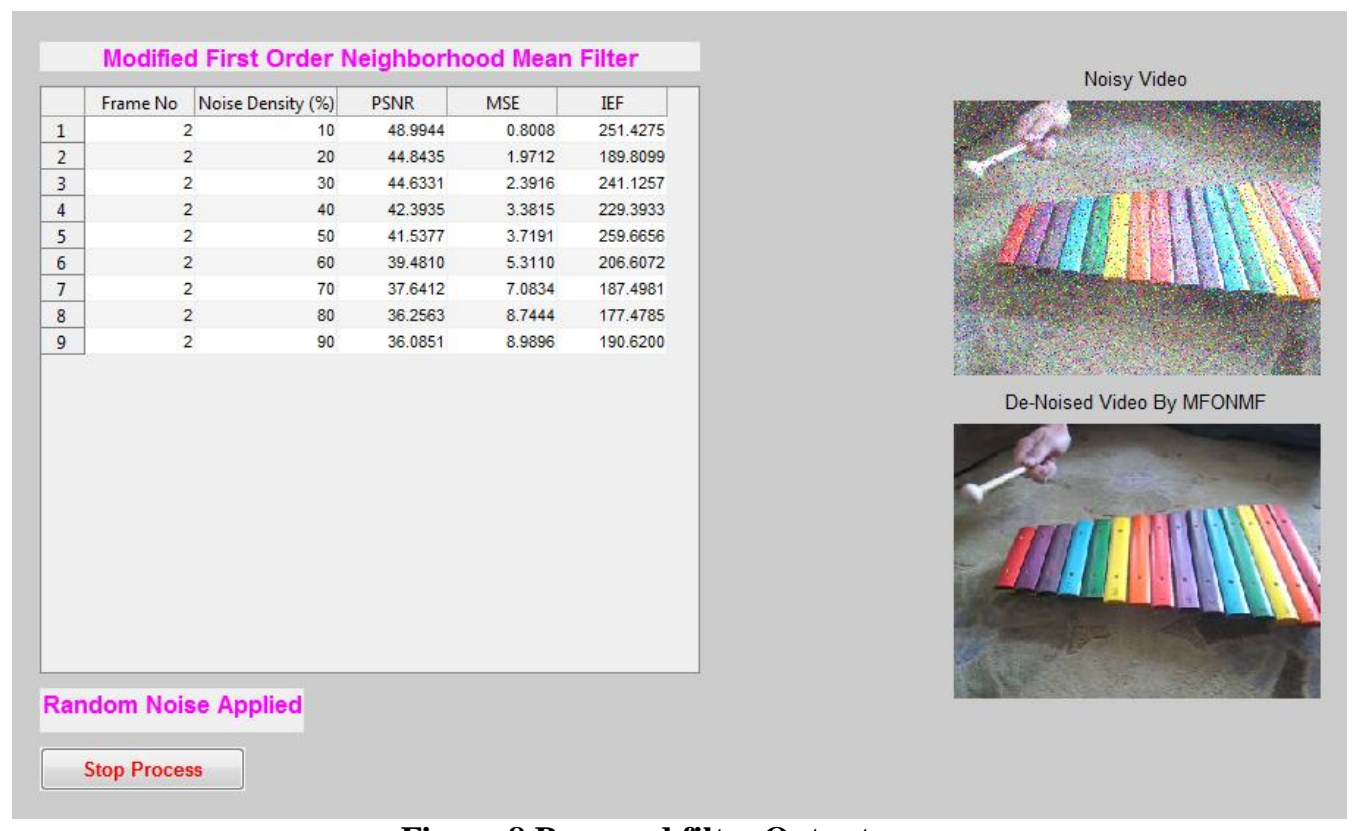

Figure 8 Proposed filter Output

Table 1: Comparison of PSNR Values of Different Algorithms

\begin{tabular}{|c|c|c|c|c|c|c|c|c|c|}
\hline \multirow{2}{*}{$\begin{array}{c}\text { Proposed } \\
\text { Filter }\end{array}$} & \multicolumn{10}{|c|}{ Noise Density (\%) } \\
\cline { 2 - 10 } & 10 & 20 & 30 & 40 & 50 & 60 & 70 & 80 & 90 \\
\hline MF & 28.49 & 25.75 & 21.84 & 18.40 & 14.73 & 12.23 & 9.98 & 8.02 & 6.57 \\
\hline AMF & 21.98 & 21.92 & 21.47 & 21.40 & 20.65 & 18.40 & 14.85 & 11.29 & 8.06 \\
\hline PSMF & 23.34 & 22.13 & 21.47 & 19.02 & 16.45 & 14.67 & 11.90 & 10.9 & 9.07 \\
\hline DBA & 25.75 & 21.84 & 18.40 & 17.73 & 17.23 & 12.98 & 11.02 & 9.09 & 6.99 \\
\hline MDBA & 27.89 & 26.45 & 24.56 & 23.45 & 22.13 & 21.47 & 20.04 & 17.23 & 15.56 \\
\hline MDBUTMF & 28.98 & 25.67 & 24.73 & 22.13 & 21.47 & 21.40 & 20.65 & 18.40 & 16.85 \\
\hline MNF & 35.09 & 33.45 & 30.34 & 28.90 & 27.90 & 25.67 & 24.73 & 22.13 & 21.47 \\
\hline MFONMF & $\mathbf{4 8 . 1 2}$ & $\mathbf{4 5 . 0 3}$ & $\mathbf{4 2 . 1 2}$ & $\mathbf{3 9 . 2 3}$ & $\mathbf{3 8 . 0 1}$ & $\mathbf{3 6 . 9 8}$ & $\mathbf{3 6 . 6 7}$ & $\mathbf{3 5 . 7 3}$ & $\mathbf{3 4 . 1 3}$ \\
\hline
\end{tabular}

Table 2: Comparison of IEF Values of different Algorithms (Phase 2)

\begin{tabular}{|c|c|c|c|c|c|c|c|c|c|}
\hline \multirow{2}{*}{$\begin{array}{c}\text { Proposed } \\
\text { Filter }\end{array}$} & \multicolumn{10}{|c|}{ Noise Density (\%) } \\
\cline { 2 - 9 } & 10 & 20 & 30 & 40 & 50 & 60 & 70 & 80 & 90 \\
\hline
\end{tabular}




\begin{tabular}{|c|c|c|c|c|c|c|c|c|c|}
\hline MF & 23.42 & 21.12 & 13.32 & 11.21 & 10.3 & 9.08 & 8.09 & 7.78 & 6.12 \\
\hline AMF & 19.43 & 18.1 & 17.78 & 16.0 & 13.32 & 11.2 & 10.23 & 9.08 & 8.09 \\
\hline PSMF & 29.56 & 26.78 & 21.84 & 18.40 & 14.73 & 12.23 & 9.98 & 8.02 & 6.57 \\
\hline DBA & 31.23 & 28.49 & 25.75 & 21.84 & 18.46 & 14.73 & 12.23 & 12.01 & 10.34 \\
\hline MDBA & 33.65 & 29.56 & 26.78 & 21.84 & 16.0 & 13.32 & 11.2 & 10.23 & 9.08 \\
\hline MDBUTMF & 34.54 & 32.56 & 28.78 & 24.84 & 18.40 & 18.21 & 14.73 & 12.23 & 9.98 \\
\hline MNF & 37.67 & 36.76 & 32.3 & 30.05 & 24.75 & 20.02 & 18.40 & 14.73 & 12.23 \\
\hline MFONMF & $\mathbf{2 4 8 . 7 2}$ & $\mathbf{2 3 5 . 7}$ & $\mathbf{2 3 1 . 3}$ & $\mathbf{2 2 3 . 1}$ & $\mathbf{2 2 0 . 4}$ & $\mathbf{2 0 0 . 2 0}$ & $\mathbf{1 9 2 . 1}$ & $\mathbf{1 8 0 . 0}$ & $\mathbf{1 7 6 . 2 7}$ \\
\hline
\end{tabular}

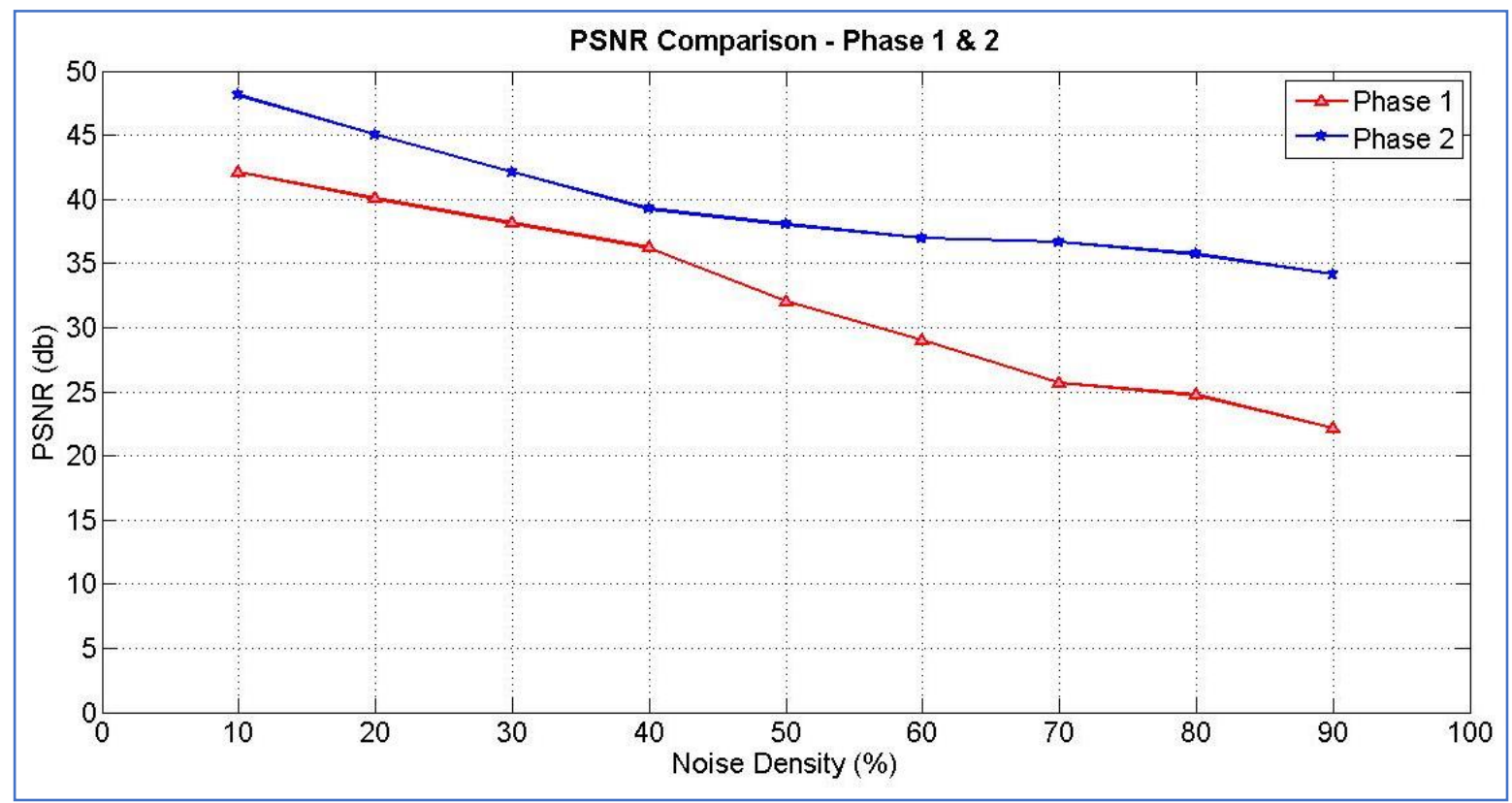

Figure 11 Noise density versus PSNR (db) 


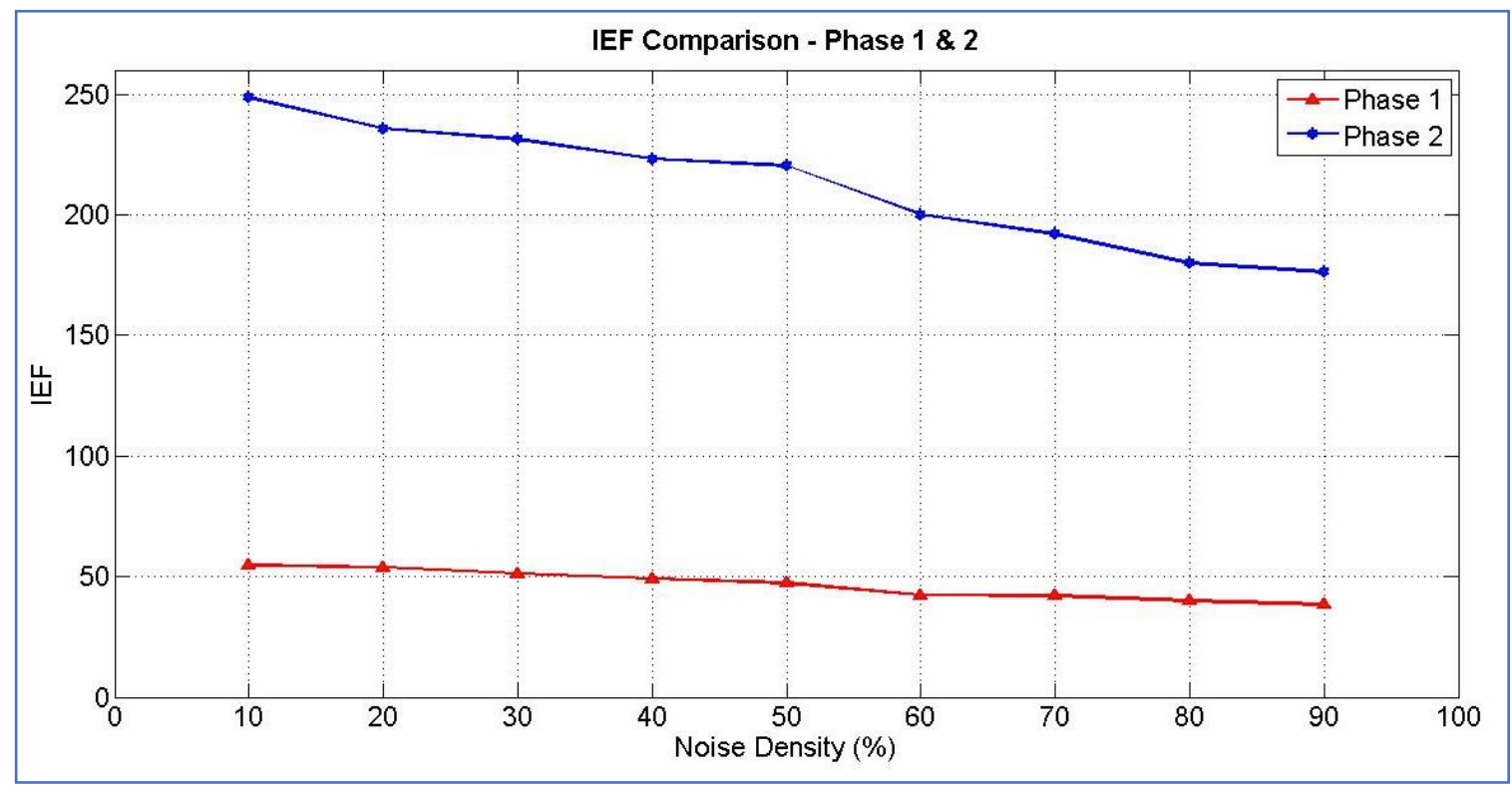

Figure 11 Noise density versus IEF

\section{Conclusion}

A new set of rules (MFONMF) has been projected for random noise elimination at advanced compactness noise eighty\% to ninety\%. This set of rules offers better effects than MF, PSMF, MDBA, AMF, DBA, and different current algorithms in stipulations of IEF and PSNR.

\section{References}

[1] T.A. Nodes and N.C. Gallagher, Jr., "The output distribution of median type filters," IEEE Trans. Communication, 32(5): 532-541, 1984.

[2] H.Hwang and R.A.Haddad, "Adaptive median filters: new algorithms \& results," IEEE Transactions on image processing, Vol. no:4, pp.499-502, 1995.

[3] J.Astola and P.Kuosmaneen, Fundamentals of Nonlinear Digital Filtering, 1997.

[4] S.Zhang and M.A. Karim, "A new impulse detector for switching median filters," IEEE signal Process.Lett., vol. 9, no. 11, pp.360-363, Nov. 2002.

[5] Fanzhi Kong, Wenbin Ma, "A Fast adaptive Mean Filtering Algorithm,", 2nd International Conference on Industrial and Information Systems, IEEE 2010.

[6] P.E. Ng and K.K.Ma, "A switching median filter with boundary discriminative noise detection for extremely corrupted images," IEEE Trans. Image Process., vol. 15, no. 6, pp. 1506-1516, Jun 2006.

[7] K.S. Srinivasan and D.Ebenezer, "A new fast and efficient decision based algorithm for removal of high-density salt and pepper noise in image," EURASIP J. Adv. Signal Process, 2010. 
[8] K.S. Srinivasan and D.Ebenezer, "A new fast and efficient decision based algorithm for removal of high-density impulse noises," IEEE Signal Processing Letters, vol. no:14 pp.189192, 2007.

[9] V. Jayaraj and D. Ebenezer, "A new switching-based median filtering scheme and algorithm for removal of high-density salt and pepper noise in image," EURASIP J. Adv. Signal Process. 2010.

[10] K.S. Srinivasan, V.Jayaraj and D.Ebenezer, “A new and efficient algorithm for removal of high-density salt and pepper noise in images and videos," Second Int. Conf. Computer Modeling and Simulation, 2010, pp. 409-413.

[11] S.Esakkirajan, T.Veerakumar, AdabalaN.Subramanyam, and C.H.PremChand, "Removal of high Density Salt and Pepper Noise Through Modified Decision Based Unsymmetric Trimmed Median Filter,” IEEE Signal Processing Letters, vol. 18, no.5, May 2011.

[12] T.M.Benazir and B.M.Imran, "Removal of High and Low Density Impulse Noise From Digital Images Using Non Linear Filter," International Conference on Signal Processing, Image Processing and Pattern Recognition, [ICSIPR) 2013.

[13] T. Vijayan , M. Sangeetha , A. Kumaravel \& B. Karthik (2020): FeatureSelection for Simple Color Histogram Filter based on Retinal Fundus Images for DiabeticRetinopathy Recognition, IETE Journal of Research, DOI: 10.1080/03772063.2020.1844082.

[14] D. S. Vijayan, A. Leema Rose, S. Arvindan, J. Revathy, C. Amuthadevi, "Automation systems in smart buildings: a review", Journal of Ambient Intelligence and Humanized Computing https://doi.org/10.1007/s12652-020-02666-9

[15] Vijayan T, Sangeetha M, A. Kumaravel, Karthik B, "Gabor filter and machine learning based diabetic retinopathy analysis and detection", Microprocessors and Microsystems,2020. https://doi.org/10.1016/j.micpro.2020.103353.

[16] Vijayan T, SangeethaM, Karthik B, "Trainable WEKA Segmentation of Retinal Fundus Images for Global Eye Disease Diagnosis Application," International Journal of Emerging Trends in Engineering Research,Vol 8, No.9, pp. 5750-5754, Sep 2020. https://doi.org/10.30534/ijeter/2020/136892020

[17] C. Amuthadevi, D. S. Vijayan, Varatharajan Ramachandran, "Development of air quality monitoring (AQM) models using different machine learning approaches", Journal of Ambient Intelligence and Humanized Computing, https://doi.org/10.1007/s12652-020-02724-2

[18] Vijayan T, Sangeetha M, A. Kumaravel, Karthik B, "Fine Tuned VGG19 Convolutional Neural Network Architecture for Diabetic Retinopathy Diagnosis," Indian Journal of Computer Science and Engineering (IJCSE), Vol. 11, No. 5, pp. 615-622 Sep-Oct 2020. DOI: 10.21817/indjcse/2020/v11i5/201105266.

[19] Vijayan T, Sangeetha M, Karthik B, "Efficient Analysis of Diabetic Retinopathy on Retinal Fundus Images using Deep Learning Techniques with Inception V3 Architecture," Journal of Green Engineering, Vol 10, Issue 10, pp. 9615-9625. Oct 2020 